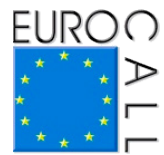

\title{
Dialogue-based CALL: an overview of existing research
}

\author{
Serge Bibauw ${ }^{1}$, Thomas François ${ }^{2}$, and Piet Desmet ${ }^{3}$
}

\begin{abstract}
Dialogue-based Computer-Assisted Language Learning (CALL) covers applications and systems allowing a learner to practice the target language in a meaning-focused conversational activity with an automated agent. We first present a common definition for dialogue-based CALL, based on three features: dialogue as the activity unit, computer as the interlocutor and negotiation of outcome through open learner production. We then report on a systematic literature review we conducted on the main scientific databases which, after filtering, resulted in 138 relevant papers which were analyzed and coded. Results show a scattered research field, with four different disciplinary approaches. We conclude with observations regarding the remaining challenges and opportunities for Intelligent CALL (ICALL) research.
\end{abstract}

Keywords: dialogue-based CALL, conversational agent, dialogue system, chatbot, ICALL, literature review.

\section{Introduction}

Second language acquisition theories have long advocated the need for meaningfocused activities, especially comprehensible interaction (Long, 1996). It has also been amply demonstrated that Synchronous Computer-Mediated Communication (SCMC), notably text-based chat, has a positive effect on the development of L2 proficiency, including speaking proficiency (Lin, 2015). Considering the lack of

1. KU Leuven Kulak, iMinds, ITEC; Université catholique de Louvain, IL\&C, CENTAL; Universidad Central del Ecuador; serge.bibauw@kuleuven.be

2. Université catholique de Louvain, IL\&C, CENTAL; thomas.francois@uclouvain.be

3. KU Leuven Kulak, iMinds, ITEC; piet.desmet@kuleuven.be

How to cite this article: Bibauw, S., François, T., \& Desmet, P. (2015). Dialogue-based CALL: an overview of existing research. In F. Helm, L. Bradley, M. Guarda, \& S. Thouësny (Eds), Critical CALL-Proceedings of the 2015 EUROCALL Conference, Padova, Italy (pp. 57-64). Dublin: Research-publishing.net. http://dx.doi.org/10.14705/ rpnet.2015.000310 
opportunities for practice with native speakers in most foreign language teaching contexts, there has thus been a steady interest in CALL systems that would allow learners to practice and develop their communicative skills through interactions in natural language with an artificial interlocutor.

Since the first attempts to tackle this problem, numerous researchers have experimented with Natural Language Processing (NLP) techniques to hold conversations with learners. However, research on this matter remains scattered across different disciplines, with only partial mutual awareness of previous works. Previous syntheses have only addressed part of the question, focusing either on speech-based applications (Eskenazi, 2009) or on text-based chatbots (Fryer \& Carpenter, 2006), or mentioning it in ICALL in general (Gamper \& Knapp, 2002).

The terms used to refer to the systems are not well established either, with important variations and multiple possible keywords. Dialogue systems, conversational agents and chatbots are sometimes differentiated on modal or technical criteria. Klüwer (2011) distinguishes dialogue systems from chatbots by their "use of more theoretically motivated techniques" (p. 3). Jokinen and McTear (2010) treat dialogue systems as necessarily spoken, and conversational agents as necessarily embodied, raising issues of multimodality and non-verbal communication; chatbots are "conversational systems" (i.e. designed for open-ended small talk) while dialogue systems are automatically task-oriented. However, the same authors recognize a growing convergence of all these systems, which blurs the boundaries (Jokinen \& McTear, 2010, p. 129). As a result, the three terms are often used interchangeably, in an unspecified usage. Bearing in mind that the challenges for dialogue management and the opportunities for language learning remain essentially equivalent, this is the position we adopted, using dialogue-based CALL as an umbrella term.

More importantly, we first propose an operational definition of dialogue-based CALL. This definition served as the main inclusion criteria in the systematic literature review. Analyzing the existing research on the topic, we identified the most important trends and some challenges for future research.

\subsection{Towards an operational definition}

It is possible to define dialogue-based CALL in a minimal way as (1) dialoguebased (2) interactions with a computer for language learning purposes. The second element sets us inside tutorial CALL, in contrast with computer-mediated 
communication, where interactions are with other humans via a computer. "Dialogue-based" makes the distinction with item-based approaches, which have been dominant in autonomous CALL applications. Nevertheless, this definition also applies to any form of interaction that takes the form of a dialogue, such as branching dialogues (conversation tree with a limited choice of utterances to select from, often used in adventure games) or systems that do not take into account what the user has previously uttered (certain question-asking systems). It is thus important to state a third characteristic: (3) the interactions must allow a certain negotiation of outcome (Young, 1988) through open learner output. It is this possibility to negotiate the outcome of the interaction, by uttering a free range of text or speech, that makes it, at the same time, complex to develop, regarding the required natural language processing in the background, and potentially very beneficial for language learning, as it enables the learner to freely build his own meaning.

\section{Method}

\subsection{Collection of a corpus of studies}

We performed an extensive search on the leading scientific databases (Web of Science, Scopus, Proquest), using all the possible keywords referring to dialogue systems for language learning, obtaining 604, 494 and 1003 hits respectively (with important overlap). We completed this retrieval process through forward citations and ancestry search from the previous relevant hits. Only peer-reviewed scientific documents (journal papers, conference papers and edited book chapters) and doctoral dissertations were included in our corpus. We then used the above-stated defining features to select papers about dialogue systems only. We discarded papers not directly related to language learning (e.g. only mentioning it as a potential application). At the end of the inclusion/exclusion process, 109 relevant papers remained.

\subsection{Analysis}

11 remaining papers were manually assessed for system, technological and evaluation aspects, as well as bibliographical information. These characteristics were coded and analyzed mainly in a qualitative manner (see section 4), but also in a quantitative way. The frequencies of all the terms referring to dialogue systems were computed and used as variables in a Principal Component Analysis (PCA). The resulting graph (Figure 2) shows the main variation tendencies, the relationships between terms and the projection of the papers on this variation space. 


\section{Results}

As mentioned above, there is a wide diversity of terms used to refer to dialoguebased CALL. Out of 109 papers, we identified 49 different terms, ranging from agent-mediated language-learning environment to voice-interactive CALL. Some papers use more general keywords, which tend to conceal the specificity of the system (e.g. virtual world, game), while others coin their own (28 terms are used once). The most discriminant terms are intelligent tutoring system, chatbot (or chatterbot), conversational agent, and dialogue system. As shown in Figure 1, dialogue system is the most frequent (58 papers mentioned it), probably because it is associated with an important research strand in natural language processing (Jokinen \& McTear, 2010). However, what does not appear here is the divergence between papers in the use of certain terms.

Figure 1. Chronological evolution of main key terms used in papers

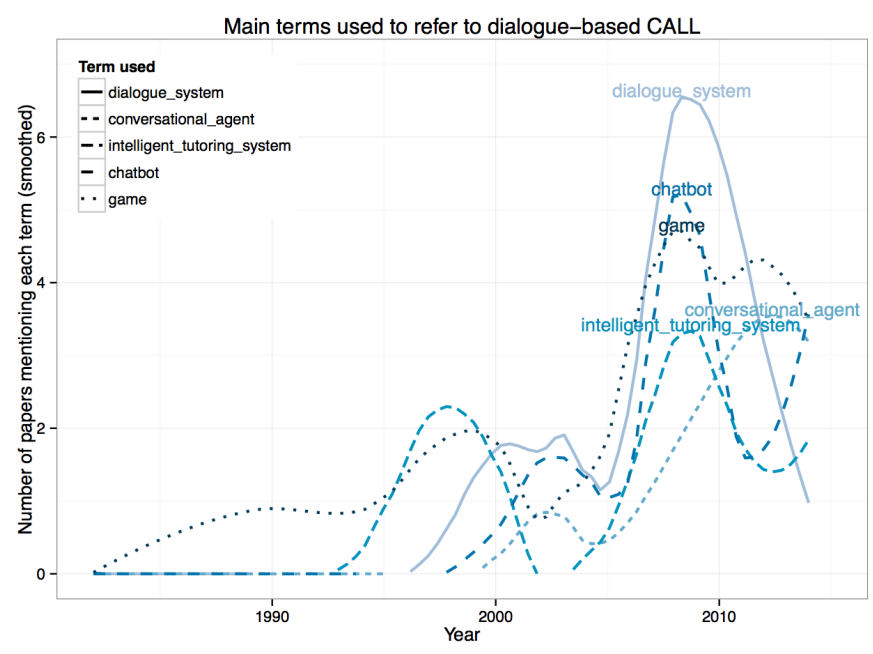

The results from the PCA, presented in Figure 2, help us distinguish different tendencies and clusters among papers. The fact that chatbot and dialogue system are on opposite sides of the $y$-axis indicates a negative correlation on the second principal component: papers mentioning one usually do not (or very rarely) mention the other. On the contrary, conversational agent is used globally in a similar way as dialogue system.

Meanwhile, the first principal component (x-axis) seems to correspond to the importance of the application for language learning: papers on the positive side 
of the axis tend to be mostly focused on the technological aspects, while those on the left tend to attribute more importance to the analysis of the language learning process. In this sense, the latter commonly use terms like tutoring systems and ICALL.

Figure 2. Projection of variables (terms frequencies, as lines) and observations (papers) on a bidimensional plot with two principal components (out of 5)
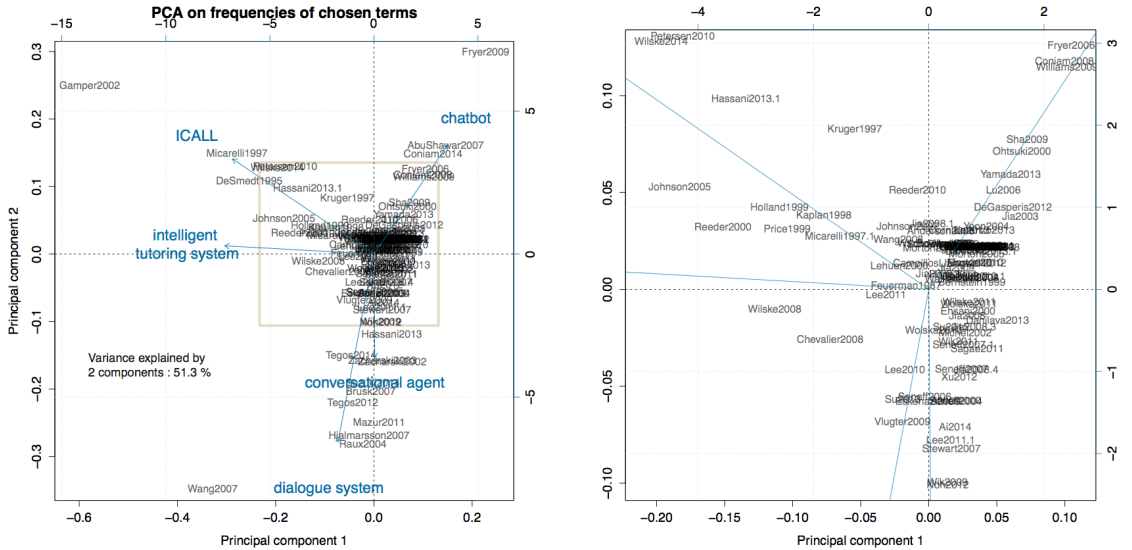

These exploratory analyses show there are different clusters of research on dialoguebased CALL. Through an interpretative and qualitative analysis, we identified four groups of papers, coming from different disciplines. They are presented in Figure 3.

The first group embraces research on Intelligent Tutoring Systems (ITS). ITS existed previously as item-based activities for form-focused practice, but the 1980s and 90s saw many efforts to develop more communicative, dialogue-based activities as part of ITS. Most papers published in this trend show a particular attention to the provision of automated corrective feedback to the learner, but little consideration for dialogue management and natural language generation.

The second group to emerge is related to games and virtual worlds. Many efforts are contiguous to ITS, with various systems qualifying as both. The gaming side of dialogue systems for language learning has also led to the most important commercial applications (e.g. Johnson, 2007).

The third group encompasses research on (spoken) dialogue systems and (embodied) conversational agents. It arises mainly from researchers in NLP who 
decided to apply these techniques to L2 learning (e.g. Morton, Gunson, \& Jack, 2012). Here, the focus is predominantly on the technological challenges that such an endeavor poses. It is probably the research area that presents the most significant technological advances and, consequently, it is also the most active.

The last group, focusing on chatbots, is the most different. Chatbots, the descendants of ELIZA (Weizenbaum, 1966), are text-based conversational systems. The diffusion of an accessible framework for programming chatbots, AIML, and the popularity of chatbots' competitions, emulating the Turing test, contributed to the creation of countless amateur chatbots. Some research on their application for language learning has been conducted (e.g. Coniam, 2014), but research on this area regularly fails to connect to the parallel work carried out on dialogue systems.

Figure 3. Research on dialogue systems for language learning which appeared in four different disciplines

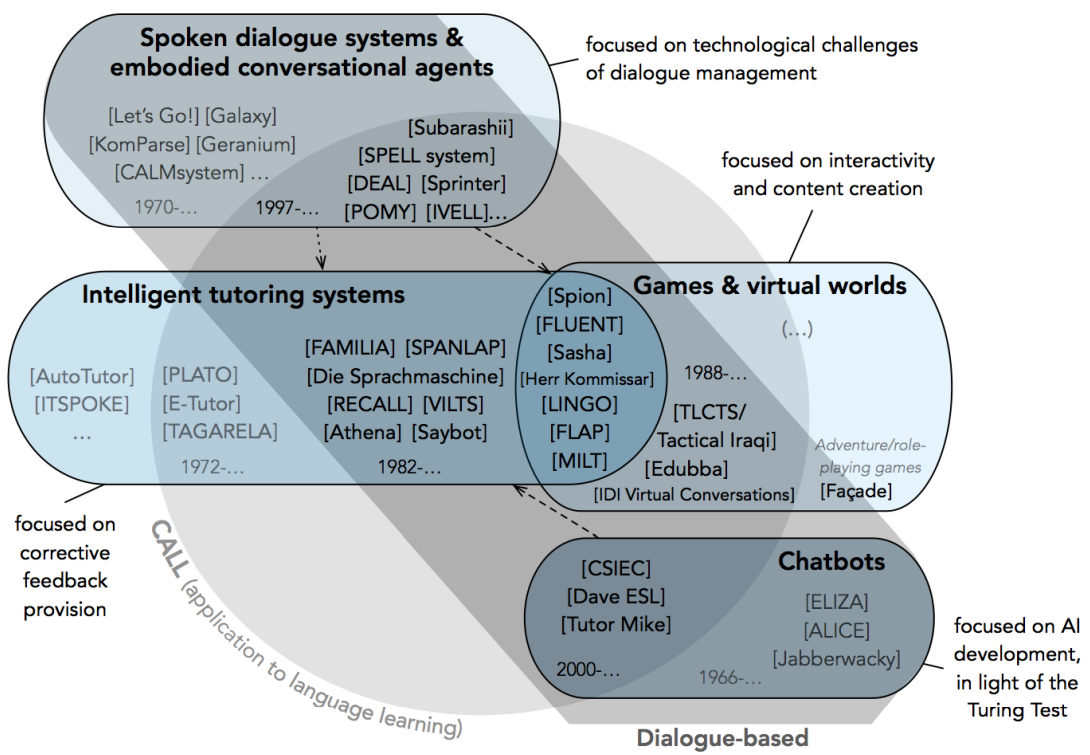

\section{Conclusions}

We have presented an operational definition of dialogue-based CALL, as dialoguebased interactions with a computer allowing negotiation of outcome through open learner. Such systems have been investigated under various terms and from various perspectives in the past, with complementary interests, bridging CALL, natural 
language processing, games and artificial intelligence. However, no common framework has been made available, and studies of the effectiveness on L2 learning lack generalizability. Therefore, there is a crucial need for more research and development on this topic.

\section{Acknowledgments}

This research is supported by Secretaría de Educación Superior, Ciencia, Tecnología e Innovación (SENESCYT) from Ecuador, under Doctoral Research Grant 2014-AR2Q7873, and is conducted jointly at KU Leuven Kulak and Université catholique de Louvain in Belgium.

\section{References}

Coniam, D. (2014). The linguistic accuracy of chatbots: usability from an ESL perspective. Text \& Talk, 34(5), 545-567. doi:10.1515/text-2014-0018

Eskenazi, M. (2009). An overview of spoken language technology for education. Speech Communication, 51(10), 832-844. doi:10.1016/j.specom.2009.04.005

Fryer, L., \& Carpenter, R. (2006). Bots as language learning tools. Language Learning \& Technology, 10(3), 8-14.

Gamper, J., \& Knapp, J. (2002). A review of Intelligent CALL systems. Computer Assisted Language Learning, 15(4), 329-342. doi:10.1076/call.15.4.329.8270

Johnson, W. L. (2007). Serious use of a serious game for language learning. In Proceedings of the 2007 Conference on Artificial Intelligence in Education: Building Technology Rich Learning Contexts That Work (pp. 67-74). Amsterdam: IOS Press. Retrieved from http://dl.acm.org/ citation.cfm?id=1563601.1563617

Jokinen, K., \& McTear, M. F. (2010). Spoken dialogue systems. San Rafael, CA: Morgan \& Claypool. Retrieved from http://www.morganclaypool.com/doi/abs/10.2200/ S00204ED1V01Y200910HLT005

Klüwer, T. (2011). From chatbots to dialog systems. In D. Perez-Marin \& I. Pascual-Nieto (Eds.), Conversational agents and natural language interaction: Techniques and Effective Practices (pp. 1-22). Hershey, PA, USA: IGI Global. doi:10.4018/978-1-60960-617-6.ch001

Lin, H. (2015). A meta-synthesis of empirical research on the effectiveness of computer-mediated communication (CMC) in SLA. Language Learning \& Technology, 19(2), 85-117.

Long, M. H. (1996). The role of the linguistic environment in second language acquisition. In W. C. Ritchie \& T. K. Bhatia (Eds.), Handbook of second language acquisition (pp. 413-468). San Diego, CA: Academic Press. doi:10.1016/b978-012589042-7/50015-3

Morton, H., Gunson, N., \& Jack, M. A. (2012). Interactive language learning through speechenabled virtual scenarios. Advances in Human-Computer Interaction, 2012, e389523. doi: $10.1155 / 2012 / 389523$ 
Serge Bibauw, Thomas François, and Piet Desmet

Weizenbaum, J. (1966). ELIZA: a computer program for the study of natural language communication between man and machine. Communications of the ACM, 9(1), 36-45. doi:10.1145/365153.365168

Young, R. (1988). Computer-assisted language learning conversations: negotiating an outcome. CALICO Journal, 5(3), 65-83. 


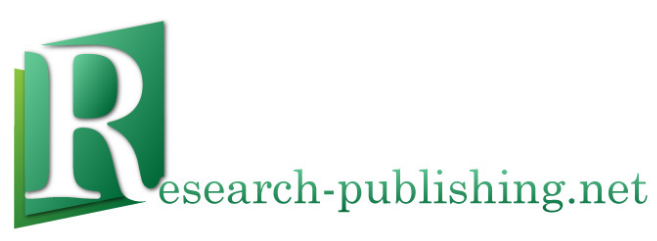

Published by Research-publishing.net, not-for-profit association Dublin, Ireland; info@research-publishing.net

(C) 2015 by Research-publishing.net (collective work)

(C) 2015 by Author (individual work)

Critical CALL - Proceedings of the 2015 EUROCALL Conference, Padova, Italy Edited by Francesca Helm, Linda Bradley, Marta Guarda, and Sylvie Thouësny

Rights: All articles in this collection are published under the Attribution-NonCommercial -NoDerivatives 4.0 International (CC BY-NC-ND 4.0) licence. Under this licence, the contents are freely available online (as PDF files) for anybody to read, download, copy, and redistribute provided that the author(s), editorial team, and publisher are properly cited. Commercial use and derivative works are, however, not permitted.

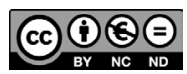

Disclaimer: Research-publishing.net does not take any responsibility for the content of the pages written by the authors of this book. The authors have recognised that the work described was not published before, or that it is not under consideration for publication elsewhere. While the information in this book are believed to be true and accurate on the date of its going to press, neither the editorial team, nor the publisher can accept any legal responsibility for any errors or omissions that may be made. The publisher makes no warranty, expressed or implied, with respect to the material contained herein. While Research-publishing.net is committed to publishing works of integrity, the words are the authors' alone.

Trademark notice: product or corporate names may be trademarks or registered trademarks, and are used only for identification and explanation without intent to infringe.

Copyrighted material: every effort has been made by the editorial team to trace copyright holders and to obtain their permission for the use of copyrighted material in this book. In the event of errors or omissions, please notify the publisher of any corrections that will need to be incorporated in future editions of this book.

Typeset by Research-publishing.net

Fonts used are licensed under a SIL Open Font License

ISBN13: 978-1-908416-28-5 (Paperback - Print on demand, black and white)

Print on demand technology is a high-quality, innovative and ecological printing method; with which the book is never 'out of stock' or 'out of print'.

ISBN13: 978-1-908416-29-2 (Ebook, PDF, colour)

ISBN13: 978-1-908416-30-8 (Ebook, EPUB, colour)

Legal deposit, Ireland: The National Library of Ireland, The Library of Trinity College, The Library of the University of Limerick, The Library of Dublin City University, The Library of NUI Cork, The Library of NUI Maynooth, The Library of University College Dublin, The Library of NUI Galway.

Legal deposit, United Kingdom: The British Library.

British Library Cataloguing-in-Publication Data.

A cataloguing record for this book is available from the British Library.

Legal deposit, France: Bibliothèque Nationale de France - Dépôt légal: décembre 2015. 